\title{
La Praxiología motriz: presente, pasado y futuro. Entrevista a Pierre Parlebas
}

Jorge Ricardo Saraví ${ }^{1}$

\begin{abstract}
Resumen: En este texto se presenta una entrevista a Pierre Parlebas, Doctor de Estado "Es lettres et sciences humaines" por la Université Paris V y la Ecole Pratique des Hautes Études, Doctor Honoris Causa por la Universidad de Lleida, España y Ex- Decano de la Facultad de Ciencias Sociales, Sorbona, París. En el diálogo con Jorge Ricardo Saraví se analizan problemáticas referidas a la Praxiología Motriz en tanto Ciencia de la Acción Motriz, sus alcances, y sus dificultades para consolidarse como conocimiento científico. Parlebas desarrolla un amplio recorrido por diversos autores y fundamentos teóricos que fueron el basamento de sus investigaciones y publicaciones. Asimismo arroja una mirada retrospectiva respecto a los orígenes de la Praxiología Motriz, así como su relación con la Educación Física y sus perspectivas a futuro. Palavras-chave: Educación Física. Conocimientos científicos. Investigación científica. Entrevista.
\end{abstract}

El Doctor Pierre Parlebas, a quien agradezco profundamente su gentileza y su disponibilidad, me recibió en su casa en las cercanías del centro del París, a principios de junio de 2009². Dialogamos de manera muy distendida y amable durante una hora y cuarenta y cinco minutos. En esta entrevista intenté encontrar respuestas a algunas preguntas que me surgían a partir de la lectura de los textos del Dr. Parlebas y de su propia trayectoria. Espero que también sean de interés para los lectores.

Jorge Saraví, marzo de 2012.

\footnotetext{
'Departamento de Educación Física. Facultad de Humanidades y Ciencias de la Educación, Universidad Nacional de La Plata. La Plata, Argentina. E-mail: jrsaravi@gmail.com

${ }^{2}$ La entrevista fue realizada en el marco de una estadía en la Universidad París V, UFR - STAPS (Unité de Formation et de Recherche en Sciences et Techniques des Activités Physiques et Sportives), mayo-junio de 2009. Programa de Becas de Movilidad Docente a París (Francia), Secretaría de Políticas Universitarias, Ministerio de Educación de la Nación de la República Argentina.
} 
Jorge Saraví (E): La idea de esta entrevista es trazar un recorrido de la praxeología motriz. Comienzo entonces, por un punto de partida ¿Qué rol jugaron las teorías estructuralistas en su enfoque? $\mathrm{O}$ en todo caso, el estructuralismo...

Pierre Parlebas (P): Habría que definir el estructuralismo, no es fácil, pero a decir verdad hay que partir de la base. La base es que yo tenía una formación en educación física, en deporte, pero, independientemente de mis años en el INSEP, en la Escuela Normal, luego hice la formación completa en psicología, una especialización en lingüística, y una maestría en matemáticas aplicadas a las ciencias humanas. Quise tener una formación científica rigurosa, provista de varias disciplinas. Esto quiere decir que pasé por las obligaciones de los exámenes, de la producción universitaria. Aclaro esto para remarcar que no se puede elaborar conocimiento científico y teorías a partir de la nada, nos anteceden los conocimientos desarrollados por nuestros precursores. Por lo tanto, como todo investigador, me he enriquecido con los aportes de la psicología, la lingüística, la matemática, y agrego la etnología y la antropología, todos fueron decisivos.

Todo empezó con la psicología. Durante mucho tiempo en psicología se explicaron los fenómenos desde el asociacionismo, es decir que el aprendizaje era entendido como asociaciones sucesivas, y sobre todo el aprendizaje motor. Se decía, por ejemplo para el ski: empezamos aprendiendo tal gesto, luego agregamos tal otro, el movimiento de brazo, y luego la suma de todo eso forma el movimiento completo. Lo mismo para la gimnasia en aparatos. Hay textos al respecto, de autores que han desarrollado ese modo de aprendizaje asociacionista. Esto estaba todavía vigente cuando yo era estudiante de educación física. Luego, en el transcurso del siglo XX, nació la corriente llamada Gestalt, que es la psicología de la forma. Esta corriente no insistía en la suma de partículas, sino sobre la emergencia de una totalidad, de una estructura, de una forma, de una Gestalt. Entonces, cuando yo era estudiante de psicología, siendo ya profesor de educación física, reflexionaba constantemente sobre los lazos que podían existir entre las prácticas que hacía con mis alumnos y la 
enseñanza que recibía en ciencias humanas y sociales. Enseguida me di cuenta de que la Gestalt aportaba un elemento que se evidenciaba en la práctica: cuando enseñaba figuras bastante simples con los aparatos, como los balanceos y el kip por ejemplo, me di cuenta de que había que repetir gestos, ritmos, y luego, en un momento dado: ¡paf!, se llegaba a la barra como por milagro, porque se había hecho coincidir bien la estructura muscular y articular con el tiempo necesario para lograr el ejercicio. Entonces me dije: eso es la Gestalt, es el ¡Eureka!, la estructura global. Bueno, es un ejemplo, pero se puede ver lo mismo en la natación, o en toda actividad en la que haya habilidades, es decir técnicas bastantes complejas que hay que adquirir.

Es así entonces que nació la idea de estructura a partir del trabajo de campo, de la toma de conciencia de que no es la adición de pequeños aprendizajes segmentados lo que permite llegar al movimiento complejo, sino que es el logro repentino a partir de un reconocimiento, de una Gestalt, de un esquema global. Esto explica por qué recurrí también a los trabajos de Piaget, con la noción de esquema, que también forma parte de la psicología de la forma.

Esto fue el comienzo, pero era insuficiente para avanzar. Para eso estuvo la lingüística, de Martinet, de Jakobson, que pusieron en evidencia el sistema fonológico. Durante siglos los trabajos sobre la lengua se perdían en consideraciones tales como si hay o no una lengua madre, o desde la filología se buscaban explicaciones literarias, históricas, que si bien eran interesantes no daban la clave del lenguaje; y la clave del lenguaje es la fonología, es el sonido que habla, que da sentido y eso es el descubrimiento de la Escuela de Praga, de la mano de Trubetzkoy, Martinet, Jackobson y otros. Antes de hacer mis estudios en lingüística era psicólogo, y a pesar de que me habían hablado mucho del lenguaje, nunca había comprendido, y nunca me habían explicado lo que era el sistema fonológico. Es decir que todos hablamos y nos entendemos bien, cuando hablamos la misma lengua, pero ninguno de nosotros tiene un conocimiento sobre el sistema que utilizamos. Es extraordinario. Por supuesto fui a la escuela maternal y al Jardín de Infantes, grabé a niños de 1, 2, 3, 4, 5, 6 años, 
para estudiar cómo era aprendido el sistema y pude ver que hay una progresión en el aprendizaje y que en un momento dado el niño, sin haberlo aprendido todo, incorpora el sistema y comienza a hablar correctamente, sin tener conciencia de ello. Y nosotros, psicólogos, deberíamos haber sabido todo eso. ¿Cómo puede ser que se utilice un sistema tan extraordinario sin tener conciencia de él, sin tener una lucidez de lo que se hace? Si le pides a alguien explicaciones sobre el sistema fonológico, no va a saber nada al respecto, como cualquiera de nosotros antes de haberlo estudiado. Entonces ahí me di cuenta en primer lugar de que hay una estructura extremadamente fuerte, que es el sistema fonológico, y que explica muchas cosas, no entraré en detalles, y en segundo lugar que ese sistema no es comprendido, no es conciente. Ahí estamos realmente en la noción de estructura.

Saussure no habla de estructura, él emplea la palabra sistema, que es lo mismo. Es la idea de sistema, además actualmente se vuelve al vocablo de Saussure y se habla de sistema y de la sistémica, y hay una tendencia a no emplear más el término estructura porque tiene una connotación negativa. Se ataca al estructuralismo de una forma un poco tonta, pero bueno, es así...

Luego de la psicología y la lingüística estudié sociología, publiqué artículos, preparé una tesis doctoral de Estado, y me interesó mucho la etnología y la antropología. Y es entonces cuando leí con mucha atención a Lévi-Strauss, que es el gran pensador de nuestro siglo. Es un autor de una calidad verdaderamente sorprendente. Si uno relee lo que escribió en los años cincuenta, sigue en gran parte vigente. Es realmente... particular. Se inspiró mucho del modelo fonológico, por lo tanto linguiístico, para reinterpretar los fenómenos etnológicos, sociales, de estructura social, estructura de parentesco, los mitos, las masas, etc. Pero digamos que él no aplicó simplemente la lingüística a la antropología sino que antes de conocer a Jakobson ya tenía esta idea de la noción de estructura, de organización macroscópica, pero Jakobson realmente lo clarificó y le proporcionó una metodología de estudio. 
Por lo tanto otra fuente de inspiración es Lévi-Strauss, la antropología, Jakobson, y por último agregaría las matemáticas. Cuando hice mis estudios de psicólogo a la vez me interesaron el psicoanálisis con Lagache, y la psicología experimental, con Fraisse. Me interesaban los dos: el psicoanálisis por la significación profunda, que abría puertas hacia toda una subjetividad cargada de sentido, y además a la experimentación que permitía corroborar todo lo que se decía por medio de resultados medidos. Hay enfrentamientos entre quienes defienden los estudios cualitativos y los que defienden los estudios cuantitativos. Yo estoy interesado en los dos y creo que se puede llevar a cabo perfectamente una investigación apoyándose a la vez en el modelo cualitativo y el cuantitativo, sin que haya contradicciones. Por lo tanto estudié matemáticas. Había estudiado estadística en psicología, pero las matemáticas son realmente diferentes, especialmente en la Escuela Francesa, con el grupo de la Escuela de Altos Estudios, en el que estaban Guilbaud, Barbut, etc., matemáticos que se interesaron por las ciencias sociales de forma muchas veces brillante, como lo hizo por ejemplo Guilbaud. Esta perspectiva finalmente ofrecía una estructura, una representación verificable, matematizable, que se prestaba a operaciones y que entonces podía transformarse en un soporte experimental y ayudar al procesamiento de datos.

En fin, mi respuesta es bastante larga, pero hay que responder así, porque no hay que creer que las cosas salen de la nada. La praxiología motriz es una creación de esa época. Empleé la palabra praxiología porque contenía la praxis y no quería que ese trabajo, esa corriente, fuese asimilada a la biología, sino que realmente se vinculara al hombre y su conducta, por lo tanto el término era praxis, acción. El término praxiología lo usaron antes varios autores, incluso a fines del siglo XIX, pero en un sentido diferente: no tenían la misma metodología, ni el mismo objetivo.

Actualmente la palabra ha resurgido y veo muchos artículos que hablan de praxiología motriz. Está bien, pero el fundamento, el origen del empleo que hice de la palabra praxiología motriz está 
ligado al aporte de la psicología, de la Gestalt, de la antropología y la etnología, de la lingüística y la matemática.

E: Agrego algo: entonces no podemos decir que la praxiología motriz se inspiró solamente del estructuralismo...

P: Claro, pero yo no usé nunca la palabra "estructuralista", porque es un término producto de una polémica, de un debate que sobrepasaba el aspecto científico y pasa a ser pasional. Se puede polemizar, de acuerdo al interés, pero hay que distinguir eso de la investigación científica. Yo no quise situarme en esa perspectiva, pero podemos usar la palabra "estructural". Si estructural quiere decir que se apoya en estructuras, sí, por supuesto que soy estructural. En cambio, estructuralismo es un monismo. Todas las palabras que terminan en "ismo" son peligrosas porque se repliegan, se cierran sobre una exclusividad, y eso no es bueno. La ciencia necesita confrontaciones para evolucionar, si no, se enquista.

Por lo tanto la noción de estructuralismo la podemos utilizar desde una perspectiva muy vaga, para calificar posiciones un poco rígidas, pero no es en absoluto nuestra posición.

E: ¿Usted mencionó a Fraisse?

P: Sí, Paul Fraisse. Era un psicólogo, presidente de la asociación de psicólogos internacionales, era una gran nombre de la psicología experimental, que era profesor en la Sorbona; cuando yo estudié se llamaba solamente la Sorbona, no había ni Universidad Paris I ni Universidad Paris II, y los profesores de la Soborna eran todos quienes habían hecho una Tesis de Estado, en esa época una Tesis, si tenía éxito, era una obra que llegaba a ser conocida por todo el mundo. Muchas obras fundamentales que surgieron como corrientes del siglo XX son Tesis de Estado, son trabajos que se hacían entre 12 y 15 años (hoy una tesis de Doctorado se hace en 3 años). Merleau Ponty, Boudon, Bourdieu, Foucault hicieron Tesis de Estado. Relacionados con el deporte y la Educación Física son muy pocos los que hicieron una Tesis de Estado: Bouet (significación del deporte), 
Ullmann (historia de la Educación Física), Brohm (sociología política), yo mismo... A partir de la obra de mi Tesis de Estado, hubo dos textos que aparecieron: el Léxico que es una parte, Elementos de sociología del deporte es otra parte de mi tesis, y eso no es ni siquiera la mitad de mi Tesis de Estado. Hay todo un trabajo experimental que yo no podía publicar en Educación Física porque se decía " es demasiado complicado, es demasiado matemáticas "... En Educación Física no se puede publicar mucho que sea científico, en la revista EPS $^{3}$ en general se publican discursos... Cada vez que yo proponía un articulo se decía " es demasiado intelectual ", etc; el primer articulo que publiqué en EPS, que se llamaba "L'Education Physique en miettes (La Educación Física en migajas), me lo rechazaron. Yo era un joven profesor, lo presenté y me dijeron no es interesante y me fui, pero el problema es que lo que yo había escrito fue leído por otras personas, por profesores de universidades y entre ellos Jacques Ulmann, a quien yo critiqué en el artículo. Sobretodo subrayando el interés de su trabajo, pero al mismo tiempo lo critiqué porque el señalaba el interés de los valores y de la técnica (pero él no introducía el pasaje entre los valores y la técnica), y lo que yo intente hacer fue de mostrar que entre los valores, la ética y la técnicas físicas, estaban todas las conductas motrices, estaban todos esos procesos de incorporación de la conducta motriz. El insistió con los redactores en jefe para que no se publique mi artículo. Mi texto llegó a las manos del responsable de investigación de la Sorbona, que en esa época era responsable de la opción Educación Física, y él dijo -es formidable- y lo difundió en toda Francia. Eso llegó a la revista EPS y luego ellos lo publicaron.

Lo que me daba energía, lo que me animaba en esa época era el trabajo de terreno, yo era profe todos los días y yo intentaba comprender eso que yo hacía y lo que pasaba en el cuerpo de mis alumnos a partir de eso que yo podía saber -eso eran las técnicas, la psicología, que era lo que yo había aprendido-. Ahí aparece mi

\footnotetext{
${ }^{3}$ Hace referencia a la Revista Education physique et sport, publicada por Editions Revue EPS y que actualmente continúa siendo editada. Más información en: http://www.revue-eps.com/fr/ la-revue_000039.html
} 
reflexión sobre la Educación Física, antes mencionada, "L'Education Physique en miettes", y los cuatro artículos que se continúan. Cuando me lo rechazan, dejé eso en un rincón y no me ocupe más, dije: yo no soy bueno para esto. Eso fue en el 66; y después brutalmente lo publicaron en el 67. Son cuatro artículos donde está todo lo esencial, la base: las conductas motrices, la acción motriz, el análisis de fenómenos, la pedagogía, la investigación científica. Fue divertido, de ver que las personas que habían sido designadas para " filtrar los conocimientos serios" (evaluar), rechazaron el articulo. Y yo me entendía bien con esas personas, no era un rechazo personal. No fue de mala intención, lo hicieron con conciencia, no se les puede reprochar, ellos razonaban con el ambiente de esa época, que no era la investigación científica; había que hacer algunos esquemas, mostrar técnicas, hacer pequeños dibujos y luego "venderlo" en la calle.

E: Con respecto a otras teorías que nutrieron el corpus de la praxiología motriz, ¿qué puede decir de la sociología de Boudon, por ejemplo, o del rol de la escuela de Palo Alto? ¿Considera que tuvieron un rol menos importante?

P: Raymond Boudon integró el jurado de mi Tesis. Sin estar necesariamente de acuerdo con él, su posición me parecía sólida, interesante, estimulante. Esto lo he dicho en numerosas oportunidades. Su análisis de los "efectos perversos" es muy interesante y siempre lo he citado tratando de mostrar el interés del mismo.

Y con respecto a la Escuela de Palo Alto, dado que también soy psico-sociólogo y tengo un conocimiento bastante amplio de los trabajos en este campo, en su mayoría americanos, he leído mucho a Bateson, entre otros, que en esa época en Francia no se conocía mucho. Su trabajo me pareció muy interesante, y se me ocurrió vincularlo con el de Boudon, es decir poner en relación la noción de "doble vínculo" con la de "efecto perverso". Es una interpretación mía, pero pienso que es muy interesante, y es por eso que he citado mucho a Bateson y publiqué muchos artículos al respecto. 
También puedo nombrar a Paul Watzlawick, en relación a la proxemia; a Birdwhistell, en relación a la kinésica; o a Goffman. Este último, en mi opinión, si bien es interesante resulta muy literario, teatral, poético, y creo que no se puede construir una sociología desde ese lugar, ya que junto con Goffman podemos tener otros diez autores que van a interpretar las cosas según su percepción... El problema de Goffman es que él interpreta según su punto de vista, pero en tanto no esté comprobado ni validado todo es posible.

E: Y también nombró a Paul Watzlawick...

P: Ah, sí, pero retoma las ideas de Bateson. Es un autor interesante, pero depende de lo que uno hace. Si realmente se trabaja en el campo de lo psicosocial, hay que tener en cuenta a Watzlawick pero no perderse en los detalles. Hay que ver lo que es directamente vinculable con las prácticas motrices, y es sobre esto que este autor retomó muchos elementos de Bateson.

Veamos ahora el caso de de la kinésica, que es muy interesante: Birdwhistell publicó una "Introducción a la kinésica" en 1952, en la que partió justamente del sistema fonológico y lo aplicó a la gestualidad, demostrando, en teoría, que la gestualidad se basa en estructuras similares a las de la fonología. Describió los gestos y las posturas que correspondían a la emisión de sentido. Es sorprendente ver que todos los autores franceses retomaron estas ideas, y la mayoría dicen "como lo muestran los trabajos sobre kinésica de Birdwhistell", pero ninguno lo verificó. Yo en cambio quiero ir al terreno. Es por eso que observé, filmé, y finalmente me di cuenta de que eso no funciona en absoluto. Por lo tanto, me dije que era falso. En el CEMEA ${ }^{4}$, por ejemplo, en el Coloquio de 1973, yo anticipé el hecho de que el sistema de Birdwhistell, por lo tanto el de la escuela de Palo Alto, no servía, estaba errado. Ahí propongo otra interpretación desde la semiótica

${ }^{4}$ CEMEA: Centre d'entraînement aux méthodes d'éducation active (Centro de Entrenamiento en Métodos de Educación Activa). Movimiento asociativo francés ligado al tiempo libre y las colonias de vacaciones, fundado en 1937. Parlebas dirige allí un grupo de investigación sobre el juego. 
de la motricidad, la semiotricidad, a partir las nociones de gestema y praxema ${ }^{5}$. Eso no funciona, cuando se quiere aplicar la psicología o la sociología a diferentes públicos como pretenden muchos de nuestros colegas, no hay que "aplicar". Hay que probar, tener un conocimiento profundo de las disciplinas científicas, que tratan esos problemas con otra mirada, para poder tomar a conciencia y comprender mejor.

E: ¿Puede ampliar sobre el efecto perverso? Ya que a Boudon no se lo conoce mucho, a diferencia de Bateson por ejemplo, que fue muy traducido al español. ¿Cómo estableció esta relación entre Boudon y la educación física?

P: La idea es interesante. De todos modos Boudon aclara que no es el primero en hablar al respecto, sino que él fue quien sintetizó la idea y la conceptualizó.

Para explicarlo, tomemos el ejemplo clásico del banco: en el banco la gente deposita dinero, oro, etc. El banco recibe todo esto y tiene un volumen inmenso, una masa monetaria importante, pero si cada persona fuera al banco a pedir su dinero, éste sería incapaz de devolverlo, porque se mueve mucho en el plano virtual. Boudon utiliza este ejemplo modelo, ya que cuando alguien va al banco a retirar su dinero, la intención es solo ésa, y no la de perjudicar a otros. Si por ejemplo se corre el rumor de que el banco no es confiable, las personas van a querer retirar su dinero. Al principio, si son pocas, el banco lo entregará, pero si pasan a ser miles, ya no podrá hacerlo. Cada persona querrá retirar su dinero con un fin personal, sin querer perjudicar a los otros, pero la suma de todos esos actos individuales crea la catástrofe. Es decir que cada uno participa en la catástrofe sin quererlo. Es la idea de que la combinación de fenómenos separados que no tienen intención negativa, desembocan en un acto negativo. También hay otros ejemplos válidos, como por ejemplo los

\footnotetext{
${ }^{5}$ Las presentaciones de ese Coloquio fueron publicadas en el texto " L'activité ludique dans le developpment psychomoteur et social des enfants ". Número especial de la revista Vers l'education nouvelle. Paris, Edición del C.E.M.E.A, 1era edición año 1973. El trabajo de Parlebas incluido en dicho texto se titula " La dynamique sociomotrice dans les jeux sportifs collectifs " (no existe traducción publicada del mismo en español o en portugués).
} 
embotellamientos de fin de semana provocados porque todos quieren salir en el mismo momento: si bien cada uno busca su placer personal, la suma de estos deseos individuales crea una situación intrincada. Esto es el efecto perverso: la combinación de actos individuales que crea un efecto colectivo global negativo.

E: Pero en la educación física ¿podría haber un efecto perverso? ¿En el campo de los juegos o del deporte?

P: Sí, por ejemplo en el juego "Gallina - zorro - víbora"6. Supongamos que soy el zorro y entonces atrapo a la gallina. Con esto creo ganar, pero en realidad estoy eliminando a la que podría atrapar a la víbora, que a su vez puede atraparme a mí. Por lo tanto, atrapando a la gallina yo creo estar ganando, pero a su vez conspiro contra mí mismo al suprimir a mi defensor.

E: ¿Es la "paradoja" del juego? ¿El juego paradójico?

P: Así es, y fuimos nosotros quienes propusimos el concepto de juego paradójico, relacionando a Bateson con Boudon. Bateson habla del doble vínculo o "double bind", que se parece mucho a lo otro.

Es decir que, en mi opinión, el trabajo científico nunca es unidisciplinario. Cada disciplina se inspira de otros trabajos. Amenudo en sociología y en psicología hay imágenes que vienen de la física, la astronomía, etc. El problema es saber utilizar bien los recursos y limitar los peligros.

E: Seguramente usted tuvo debates y combates con los defensores de otras corrientes... ¿quiénes se opusieron a la praxiología motriz y por qué? ¿Hubo un enfrentamiento entre la psicomotricidad de Le Boulch y usted?

\footnotetext{
6"Gallina zorro víbora" (Poule - renard - vipère): es un juego colectivo, practicado generalmente en el exterior, muy habitual en la escuela primaria. El principio es el siguiente: se organizan los participantes en tres equipos: los zorros, las gallinas y las víboras. El objetivo de los zorros es atrapar a las gallinas, el de las gallinas comerse a las víboras, y las víboras deben atrapar a los zorros. Esto significa que cada equipo tiene a la vez una presa y un predador. El juego es conocido por ser uno de los "juegos paradójicos": cuanto más gano, más pierdo. Por ejemplo, suponiendo que gana el equipo de los zorros, esto va a implicar una disminución de gallinas y en consecuencia un aumento de víboras, lo cual dificultará la situación para los zorros.
} 
P: Considero que el trabajo de Le Boulch es muy interesante, pero no es un autor moderno, sino que es el último de los grandes autores del pasado. Era un médico que trabajaba solo en su despacho, muy obsesionado con la fisiología, queriendo reconstruir la educación física a partir de estos datos. Elaboró ejercicios de gimnasia construida, como se hacía en esa época, y como se daba cuenta de que faltaban cosas, cada tanto agregaba una pizca de deporte, de psicología o de sociología, pero fundamentalmente su trabajo era de naturaleza fisiológica. Yo no lo conocía, lo conocí cuando yo ya era profesor y fui a hacer un cursillo con él a fines de los '60. Trató de hacer algo novedoso, y sin embargo seguía siendo la educación física del movimiento, y movimiento es el término que utilizaban Demeny o Dally, que se utilizaba en el siglo XIX.

Hay una obra de 1857, de Nicolás Dally, que tiene como título "Cinesiología, o ciencia del movimiento"7, y hoy en día, más de un siglo y medio después, se pretende elaborar la ciencia del movimiento... Mucho de lo que se dice ahora ya estaba dicho ahí. Lo interesante de ese libro es que no solo desarrolla el aspecto pedagógico de la ciencia del movimiento, sino también el aspecto terapéutico.

Cuando veo que actualmente nos hablan de la ciencia del movimiento, cuando se ve actualmente los supuestos investigadores científicos en educación física que pretenden traernos a conocimientos de fondo que datan de un siglo y medio, eso nos hace mínimamente sonreír. No es solamente una cuestión de palabras, detrás de las palabras, hay conceptos, y una teoría científica se apoya en conceptos.

Bueno, volviendo a Le Boulch y la psicomotricidad, él es el último gran representante de una educación física que se estaba terminando. Se quedó en una concepción en la que uno construía solo su sistema, que supuestamente tenía que agotar el campo de la

\footnotetext{
7"Cine?siologie, ou Science du mouvement dans ses rapports avec l'e?ducation, l'hygie?ne et la the?rapie, e?tudes historiques, the?oriques et pratiques", N. Dally, 1857.
} 
realidad. Hoy en día se trabaja de otra forma. Ya nadie es capaz de inventar un sistema que pueda dar una respuesta a todo. Lo que yo intenté hacer fue plantear una problemática lo más clara y operatoria posible, -sin estar seguro de haberlo logrado-, y lo que justamente me reprocharon los colegas fue no haber propuesto un sistema con fichas que pudieran ser aplicadas inmediatamente, lo cual rechacé, a pesar de ser lo que en realidad me podía dar dinero... (risas). En mi opinión no tenía nada que ver con la investigación científica. La misma consiste en proponer un marco teórico, conceptos, llevar a cabo experiencias, verificar lo que se dice y además contrastar con lo que hacen los otros, comparar lo que se ha escrito, etc... y ése, a mi parecer, es el nuevo movimiento de educación física, que muy pocos que lo quieren incorporar...

Recapitulando, lo que llamamos psicomotricidad era un movimiento interesante de psicólogos que finalmente se habían ocupado un poco del cuerpo, a diferencia de los anteriores que se centraban más que nada en la palabra. Se dieron cuenta de que los niños en la escuela tenían un cuerpo, descubrimiento capital (risas), y autores importantes como Wallon mostraban la importancia de la actividad corporal, especialmente de la distribución tónica y cosas como ésa. Los psiquiatras hacían lo mismo: se daban cuenta de la importancia de los datos corporales, pero de manera fragmentaria.

Me acuerdo que cuando era estudiante de psicología, estudiábamos el cuerpo a través de la patología. Por ejemplo, se hablaba desde lo privativo: inmovilidad, afasia, agnosia, es decir que el cuerpo era revelado o mostrado por sus faltas o sus patologías, y no se lo veía el cuerpo en acción, jugando al fútbol, o corriendo, por ejemplo. Uno de mis artículos de esa época trataba justamente sobre eso, sobre qué era la psicomotricidad, que por un lado era muy interesante, pero por otro muy reduccionista. Me acuerdo que al final de una clase, le pregunté a un gran profesor si no pensaba que la psicomotricidad era reduccionista, y si no importa lo que sucede en la vida cotidiana. Me respondió que eso era secundario, que el interés estaba en la patología. Sin embargo yo observaba a mis alumnos, y pensaba: ¿los niños de hoy en día acaso no pueden 
expresarse o desarrollarse mediante la actividad corporal? Y no tenían respuesta para eso. A partir de eso comencé a reflexionar. La psicomotricidad era realmente parcial y además estaba parcializada. Entonces, observando lo que pasaba y siendo psicosociologo -lo cual tiene su importancia teniendo en cuenta que la psicosociologia es la ciencia de las interacciones, me di cuenta de que los psicomotricistas quieren a los individuos como sujetos aislados-, de la misma forma que en el psicoanálisis. En psicoanálisis no sólo están solos, sino que no se mueven, únicamente se los hace hablar. Pero es interesante no solo hacerlos mover, sino de hacerlos interactuar, ponerlos en grupo. Es por eso que insistí sobre el psicodrama de Moreno, que no es diván, es la acción en una escena de teatro con muchas personas. No creo que todo pase por el lenguaje como afirma Lacan... pero eso es otro tema.

Recuerdo algo que sucedió cuando era director de una colonia de vacaciones. El lugar era magnífico, teníamos el mar muy cerca, los acantilados, la arena, bajo el sol radiante del mes de agosto... Me encontré con un grupo de profesores que trabajaban con la psicomotricidad y me pidieron un espacio para hacer sus actividades. Enseguida arreglé todo para que pudieran hacerlo y en un momento dado fui a observarlos: habían cerrado las ventanas, estaban casi a oscuras, a pesar del día magnífico que hacía afuera, y les hacían hacer tonterías a los chicos... Ahí me di cuenta del aspecto perverso de la cuestión. Les dije que si bien era interesante lo que hacían, tenían la playa, la naturaleza ahí afuera... Para vivir también es necesario que el niño conozca el mundo y se conozca a través de sus relaciones con el mundo. Ahí me di cuenta de que había que definir la psicomotricidad de otra manera diferente. Ya que hablamos de psicomotricidad, podemos utilizar también el término sociomotricidad, y darle una definición operacional: es psicomotor lo que no necesita ninguna interacción motriz con otros, y sociomotor lo que impone una comunicación, una interacción motriz con uno o varios otros. Es así como pude definir el campo psicomotor y el campo sociomotor, de forma operacional. Esto es muy revelador, pero muchos colegas no lo han seguido, no lo comprendieron, o no han querido comprenderlo. Nunca hubo oposiciones claras, sino un 
rechazo global, porque no quieren entrar en un sistema que destruya las bases del conservadurismo. Quieren conservar lo antiguo, y evitar todo enfoque nuevo. En la educación física estamos frente a un mundo muy conservador que constantemente habla de ciencia, pero casi nunca de manera seria. Esto hace que la educación física sea un conjunto de discursos, muchas veces talentosos, pero que siguen siendo discursos no controlados, literarios, más o menos oscuros, haciendo referencia a teorías sociológicas o psicológicas no comprobadas, al psicoanálisis de bazar... En fin, eso es la teoría de la educación física. Por lo tanto, cuando alguien propone cosas precisas, los colegas ni siquiera pueden refutarlas porque no cuentan con las herramientas para hacerlo, y tampoco quieren dotarse de dichas herramientas, ya que, obviamente, para objetar hay que manejar los conceptos, y tener un mínimo conocimiento en lingüística, matemáticas, en fin...

E: ¿Entonces las críticas que se hicieron a la praxiología motriz en Francia tenían que ver más con lo ideológico, o lo personal?

P: No, ni siquiera, porque al principio, antes de publicar, me llevaba muy bien con todos, era muy bien recibido en todos lados, era el alumno modelo... (risas). Pero cuando empecé a escribir artículos, pensando que todo iba a estar bien y que los colegas iban a compartir mis opiniones, vi por el contrario que desde los artículos del diario deportivo L'Equipe se me opusieron de forma violenta, difamatoria, incomprensible. Yo no estaba atacando a nadie, solo presentaba mis ideas, y sin embargo parecía que los había atacado. Por lo tanto, no puedo decir que comenzó como algo personal, aunque sí lo haya sido luego. Mis ideas molestaban a las jerarquías, porque no aceptaban que se discutiera su autoridad. En realidad lo que yo discutía eran las teorías que legitimaban su autoridad. Además hay que decir que todos aquellos que adquirieron una formación científica o pseudocientífica después de los años 70, sobre todo en el INSEP ${ }^{8}$, se formaron en un corto tiempo, por equivalencia, y ninguno, o casi ninguno de ellos tiene una verdadera formación de psicólogo o

${ }^{8}$ INSEP : Institut National du Sport et de l'Education Physique (Instituto Nacional del Deporte y la Educación Física) 
sociólogo. Lo que tienen es lo que yo llamo "un barniz científico", y se encuentran desorientados ante lo que escribo, sin posibilidad de discutir. Rechazan sin dar una crítica, no proponen nada, o lo que proponen viene de la psicología o la sociología, pero no es nada relativo a la educación física propiamente dicha. Como la sociología del deporte, por ejemplo, que está muy bien, pero si van a trabajar en ese campo, qué hacen en las STAPS ${ }^{9}$ ? Que vayan con los sociólogos... Si se quedan en las STAPS, es necesario que tengan algo para decir, y no solo retomar lo que dicen los biólogos o los sociólogos... En fin, cuando yo digo esto todos se ponen furiosos, porque doy justo en la tecla de todos los que pretenden ser psicólogos, sociólogos, historiadores o biólogos y no lo son.

En general todo esto no se comenta, pero hay que saberlo. Yo siempre formo parte de los jurados de historia o ciencias políticas por ejemplo en la Sorbona, y escucho lo que dice la gente... Dicho de otra forma, la praxiología motriz les molesta mucho.

E: ¿Usted considera que la praxiología motriz es una corriente de la educación física?

P: No, no es una corriente de la educación física, es una disciplina científica a la que uno puede dedicarse y que sirve de soporte para el desarrollo de una educación física válida y verificable. La praxiología motriz no puede ser una corriente de la educación física, ya que la educación física es una práctica, no una ciencia. Y por lo tanto la praxiología motriz no puede ser un subproducto de la educación física. Sucede lo mismo con la medicina, que no es una ciencia sino una práctica. En la práctica, el profesor crea, inventa, en función de los alumnos que tiene, del día... Por lo tanto la educación física no es una ciencia sino una práctica que se apoya al máximo en datos científicos.

E: Muchos de los autores que hablan de corrientes de la educación física hoy en día, dicen que hay una corriente, ligada a Parlebas, a la praxiología motriz...

9STAPS : Sciences et Techniques des Activités Physiques et Sportives (Ciencias y Técnicas de las Actividades Físicas y Deportivas). Es la denominación actual de la formación universitaria en Francia. 
P: La praxiología motriz es una disciplina científica que sirve, para nosotros, de soporte fundamental en Educación Física. La praxiología motriz es en cierta forma el fundamento de la educación física, desde el punto de vista de las prácticas. La praxiología pretende ser la ciencia de la acción motriz, y la educación física se basa justamente en la acción motriz. Pero inmediatamente hay otro problema que se plantea y es el de la finalidad, los valores... Una ciencia no establece valores. Es decir, podemos utilizar la educación física para formar gángsters, contrarrevolucionarios, pillos, o todo lo contrario, hombres de honor. Dependerá de los valores que se hayan propuesto a las prácticas específicas.

E: Entonces podría haber una corriente de la educación física, en tanto practica social, que se inspire en los trabajos realizados en el campo de la ciencia de la acción motriz, ¿es así?

P: Claro, eso es lo que hacemos con mi grupo, es lo que hago yo en el terreno. Desde el comienzo, desde los años 60 desarrollé métodos de la enseñanza del ski, buceo, y propuestas de juegos que se basan en eso, sí. En el CEMEA es eso lo que desarrollamos.

E: ¿Cuáles son los principales aportes de la praxiología motriz a la educación física? O aportes para los profesores de educación física para mejorar las prácticas en la escuela.

P: El primer punto, que es capital, es que la praxiología motriz dá un fundamento sólido y científico a la educación física. Esto es muy importante, ya que si no, surge la pregunta de por qué hacer educación física en la escuela. Por ejemplo: ¿de qué sirve el lanzamiento de bala? Si decimos que desarrolla la fuerza, entonces: ¿fuerza para qué? ¿Y qué tipo de fuerza? ¿Valorada por quién? ¿En qué condiciones? Tal vez para los Juegos Olímpicos, pero ¿hay que pensar que los miles de niños franceses que practican esta disciplina van a participar de los juegos olímpicos? Yo practiqué mucho la gimnasia en aparatos, horas muchas horas, pero ¿para qué sirve en mi vida? No sirve para nada. Y ése el problema: ¿para qué sirve la educación física? Incluso el football, algunos dicen que compensa la 
actividad intelectual, más que nada durante la adolescencia, pero: ¿en la vida adulta? ¿Y el rugby, además de las heridas y los moretones?

Entonces, la praxiología motriz muestra que mediante las prácticas físicas se trabaja sobre la personalidad, la inteligencia, la afectividad, las relaciones, y se sabe que interviniendo en las situaciones motrices, es posible favorecer el desarrollo de la persona. A partir de esa base, se puede ir más lejos: trabajar sobre la cooperación, sobre el conocimiento del medio, el dominio corporal desarrollando la adaptabilidad, el equilibrio de la persona. Obviamente también se podría trabajar en la lucha contra la obesidad y todo eso, pero nosotros fundamentalmente ponemos el énfasis en el plano afectivo, relacional, social, etc. Una persona puede sentir tanta plenitud con el deporte como con el arte. En general se considera normal que alguien se sienta pleno yendo a la ópera por ejemplo, pero me parece más interesante para esto las actividades en el medio natural, como el ski o el buceo, que pueden resultar mucho más motivante que estar pasivo en una silla.

Una vez que se ha demostrado que la acción motriz permite desarrollar las diferentes dimensiones, la Educación Física tiene su lugar en el sistema educativo.

E: En sus artículos usted dijo, en los años 70, que la educación física debía llegar a la revolución copernicana... ¿esto sucedió? Y si no fue así, ¿qué queda por hacer?

P: No, no sucedió por completo. Sí hubo una revolución copernicana en la perspectiva de la "Educación Nueva", en la cual yo me sitúo, con autores como Freinet, Decroly, Rousseau, etc., que implica poner al niño en el centro del sistema y por lo tanto hacer énfasis en la conducta motriz y no en la técnica. La técnica es una construcción de los adultos, a diferencia de la primera, que es una creación de cada niño, de cada persona. Hay que poner la conducta motriz en el centro del sistema, y actualmente no se hace, sino que prima el deporte, la técnica deportiva, esperando lograr performances que tienen más que ver con producciones del hombre desde una 
perspectiva económica, y no es que esté en contra, pero esto debe ser relativizado y puesto en un contexto aceptado y aceptable.

E: ¿Y qué se puede hacer para que esto cambie? ¿Qué es lo que queda por hacer?

P: Hay que formar a nuestros estudiantes en la perspectiva de esta revolución copernicana, para que se alineen sobre las bases de la Educación Nueva, como fue concebido en el CEMEA, poniendo al niño -o al adulto- en el centro de la cuestión, partiendo de su realidad, capacidades y expectativas para ayudarlo a apropiarse de los conocimientos sociales. Esto no significa obedecer a sus caprichos, sino establecer un vínculo entre la naturaleza del niño y las obligaciones sociales, transmitiéndole principios que nos parezcan esenciales para que se apropie de ellos lentamente, comprendiéndolos o eventualmente volviéndolos a poner en perspectiva.

E: ¿Usted cree que la praxiología motriz llegó a tener un lugar en los estudios académicos, en Francia, y en los conocimientos que tienen los profesores que trabajan en la escuela? ¿Cuál es la situación actual de la praxiología motriz en Francia?

P: Es muy variada. Hay establecimientos en los que los profesores se resisten a la praxiología motriz, porque les molesta o por cuestiones políticas, ya que los praxiólogos no estamos a las órdenes, sino que trabajamos en una perspectiva crítica y científica. Por lo tanto, evidentemente, no podemos ser aceptados por aquellos que quieren obediencia. En ciertos establecimientos muy politizados no funciona la praxiología. Allí quieren formar estudiantes como en una secta.

También están quienes no conocen la praxiología motriz, ya que los conocimientos científicos se expanden poco a poco, pasando muchos filtros, y hay muchas oposiciones y peleas, que hacen que los estudiantes no estén informados.

Pero, por otro lado, hay establecimientos en los que la praxiología está siendo tomada en cuenta poco a poco, y otros que se basan por completo en ella, tanto en Francia como en el extranjero. De hecho, 
hay muchas Tesis relacionadas con la praxiología motriz en Francia y en el exterior. Yo participé en más de 10 tesis en español, y hace poco fui presidente de jurado de una tesis en España y lo seré nuevamente. Y son ellos que me invitan, yo no lo pido, esto quiere decir que la praxiología motriz se transforma en lo central de su trabajo.

En Argentina, Chile, Colombia, México, Brasil, también están esos problemas, pero creo que en los países nuevos es mucho más fácil introducir la praxiología motriz que en Francia, Inglaterra o Alemania, que son países viejos. Porque nosotros, en Francia por ejemplo, tenemos muchas personas establecidas en un lugar que no quieren cambiar, mientras que en los países nuevos hay gente joven, nueva, que no lleva a cuestas un pasado estancado, y que puede hacer otras cosas. Es lo que pasó en España y es lo que puede pasar en Argentina y los países nuevos. En mi opinión, paradójicamente, allí pueden ir más rápido que en los países viejos. Actualmente España está superando en mi opinión a Italia, Inglaterra o Alemania, porque cuenta con una corriente muy fuerte de jóvenes que rechazan las ideas conservadoras, franquistas, pero también comunistas, con las que ya no se puede vivir; el colectivismo o el centralismo exacerbado ya es historia. Hay que relativizar las cosas, pasar por el fuego de la crítica y adoptar lo que parece más compatible con el avance del conocimiento, cosa que los jóvenes actualmente son perfectamente capaces de hacer. Actualmente España supera a Francia, mientras que hace 30 años era la nada.

E: Su objetivo es desarrollar una ciencia de la acción motriz: la praxiología motriz. ¿Considera que ésta llego a ser realmente una ciencia, o falta aún tiempo y trabajo para que lo sea por completo?

P: La praxiología motriz es una ciencia completa, porque una ciencia está definida por su objeto, el campo al cual se circunscribe, los métodos que utiliza, y con respecto a todo esto, la praxiología motriz no tiene problemas. Es una ciencia, pero que se encuentra en sus comienzos. Esto quiere decir que vendrán nuevos investigadores, además de los que ya hay, y superarán lo desarrollado hasta ahora con nuevos descubrimientos y trabajos que van a 
reintegrar lo que ya se hizo en una interpretación más amplia. Nosotros propusimos un nuevo paradigma que apenas está comenzando; es necesario desarrollarlo, y ésa será tarea de la gente de tu generación y las posteriores.

Sin embargo yo creía que todo iba a ir más rápido, yo era muy ingenuo. En los años '60 veía que había muchísimo por hacer y descubrir. Estaba admirado frente al campo que se presentaba, las cosas que había para hacer, éramos tan ignorantes, había tantas cosas para descubrir... El campo que se abría ante nosotros era tan amplio que pensé que todos iban a precipitarse sobre él y hacer avanzar las cosas. Pero enseguida vi, con asombro, que había un rechazo. La gente quería quedarse en las ideas antiguas, y fue necesario que lleguen los jóvenes as nuevas generaciones para revertir esa situación. Fueron los jóvenes los que lograron desbloquear la situación, no la gente de mi generación.

E: Si pudiera volver el tiempo atrás, ¿hay algo que cambiaría?

Sí, por supuesto que hay cosas que haría de otra forma, pero eso es muy ficticio, porque en realidad lo que hice fue en base mi ingenuidad de profesor joven, ya que me interesaba el mundo del conocimiento más que otras cosas. Por ejemplo, en los años '60 me propusieron ser profesor de la Sorbona y no acepté, si bien era muy halagador. No acepté porque acababa de ser nombrado en un laboratorio de investigación en educación física, y era mi área, mi interés estaba ahí. Si iba a la Sorbona iba para trabajar como psicólogo y a mi me interesaba trabajar con las prácticas físicas. La investigación era lo que me daba felicidad plena. No sé si ahora actuaría de la misma forma, pero bueno, en su momento pensé muy ingenuamente que todo iba a salir bien, pero no fue así; me di cuenta de que proponer ideas nuevas no era algo neutro ni indiferente; la gente se crispaba e incluso me odiaban, aun sin conocerme. Sorprendentemente, mis ideas se interpretaban desde un lugar político y polémico sin conexión con la realidad. Pero no me molesta, yo sigo adelante, y si volviera a empezar habría cosas que haría de otra manera, pero estoy seguro de que conservaría la perspectiva que elegí. Hace más de cuarenta años que escribí los primeros artículos, 
ninguno fue refutado y a pesar de todo lo que pasó, ahora son fuente de inspiración para nuevos trabajos. Ahora todo el mundo habla de lógica interna, de sociomotricidad, semiología, afectividad en las conductas motrices. Cuando escribí ese artículo querían arrancarme los ojos: ¿que tiene que hacer la afectividad en la Educación Física? estás loco! me decían... En su momento decir eso resultaba descabellado, pero ahora ya es algo común, es una banalidad.

Es interesante volver a los artículos de los '60, porque allí está todo. Si alguien pregunta cuales son las pruebas, que tomen esos artículos, que comparen, que los lean; hay que referirse a los textos, a los datos. En ese momento me acusaban de que no servía para nada lo que yo decía, y ahora, todos aquellos que me atacaron fueron completamente olvidados. Es decir que hay que dejar que hablen, salvo que las críticas sean interesantes. Yo espero las críticas, porque escribir un artículo científico es aceptar e incluso esperar las críticas. Un investigador sabe que es sólo un escalón de un proceso de interpretación de la realidad, y lo que espera es una crítica inteligente para poder avanzar, pero francamente yo no conozco ninguna, no he tenido ninguna.

E: Para algunos investigadores, por ejemplo aquí en Francia, el objeto de estudio es el cuerpo, y el de usted es la acción motriz...

P: Puede ser, pero el cuerpo ¿qué es el cuerpo? ¿Hablamos del cuerpo para el psicoanalista, el biólogo o el historiador? El cuerpo no tiene exclusividad. Se habla del cuerpo desde hace siglos, no es una novedad, y nunca permitió avanzar desde el punto de vista científico, sino todo lo contrario. Si por ejemplo tomamos a Descartes, era la separación de alma y cuerpo, que no fue un avance desde el punto científico, y Descartes ya no tiene vigencia en su generalidad.

Cuerpo es una palabra comodín, una palabra que permite hablar de todo. Es el objeto de los que no tienen nada que decir. Ya sé que ahí exagero, e intento ser polémico, porque se puede hablar del cuerpo de manera interesante, pero a condición de que solo sea un medio para relacionar otras cosas. Cada tanto hago referencia al cuerpo, 
pero es una vía de pasaje hacia otra cosa. En mi caso, yo lo utilizo como vía de pasaje de la acción motriz, y no como objeto. O, en todo caso, es el objeto del fisiólogo, o del etnólogo... pero, hay tantos cuerpos como disciplinas. motriz?

E: Y la última pregunta: ¿cómo ve el futuro de la praxiología

Muy brillante, bajo la pluma y el trabajo de nuestros sucesores. Es evidente que va a haber muchos investigadores que van a apropiarse de la praxiología motriz y van a desarrollarla de una manera que no se puede prever, incluso mejor que nosotros. Seguramente van a descubrir cosas que nosotros no vimos, porque la acción motriz es algo extraordinario. Cuando se examina lo que sucede en un partido de rugby, en un set de tenis, en una escalada, en el yoga, el judo, la esgrima, en el patio de una escuela, en una colonia de vacaciones todo lo que pasa por el cuerpo, bajo la forma de conductas motrices es exuberante, extraordinario. Y se conoce muy poco sobre esto. Nosotros hemos intentado arrojar las premisas, pero esto será indudablemente superado, porque pronto nosotros moriremos y otros jóvenes vendrán, sin el peso del pasado. Muchos de mis colegas actuales se han equivocado y no quieren reconocerlo. Algunos han tomado temas clásicos, el cuerpo, la sociología del cuerpo, la antropología del cuerpo, que ya habían sido ampliamente desarrolladas por los etnólogos y antropólogos, y eso les permitió hacer carrera. Actualmente, la praxiología motriz no está de moda. Si se quiere estar a la moda, hay que hablar de lo cognitivo, las neurociencias, ahí hay otras formas de hacer carrera, de tener éxito.

Los que hoy en día eligen la praxiología motriz son blanco de discusiones, pero al mismo tiempo me fui dando cuenta de que los estudiantes que se acercaban a nosotros eran los mejores, o formaban parte de los mejores, porque era gente que sabía lo que quería, que tenía experiencia y conocimiento de causa. No buscaban hacer carrera, porque nosotros éramos blanco de dificultades e incluso de la administración. Hasta fui desplazado por un ministro, no podía dar 
clases en el INSEP donde yo era profesor, fui acusado de pensamiento subversivo. Eso fue en los años 69-70. Y luego suprimieron mi laboratorio.

E: Pero era una cuestión ideológica...

P: Y sí, porque yo molestaba. Pero el Director finalmente estuvo obligado a devolverme el laboratorio porque los estudiantes fueron a verlo y le dijeron que si no lo hacía, se iba todo al diablo... Respondiendo a la pregunta, es difícil, pero los que vienen a trabajar en praxiología motriz no se arrepienten, porque se reafirman frente a los estudiantes, a los lectores, a los otros investigadores. Algunos son presidentes de federaciones deportivas, otros devienen profesores en la Universidades. En el futuro, muchos serán praxiólogos. Actualmente hay estudios que toman como punto de apoyo la praxiología motriz, por eso soy muy optimista, no tanto por nosotros, sino por mis sucesores*.

"Traducción realizada por Cristian Calvo en la cátedra "Prácticas de la Traducción" a cargo de la Prof. Ana María Gentile, Facultad de Humanidades y Ciencias de la Educación, Universidad Nacional de La Plata. 
A praxiologia motriz: presente, passado e futuro. Entrevista com Pierre Parlebas

Resumo: O presente texto apresenta uma entrevista com Pierre Parlebas, Doutor de Estado "Es lettres et sciences humaines" pela Université Paris $\mathrm{V}$ e pela Ecole Pratique des Hautes Études, Doutor Honoris Causa pela Universidad de Lleida, España e Ex- Decano da Facultad de Ciencias Sociales, Sorbonne, París. Neste diálogo com Jorge Ricardo Saraví se analizam problemáticas referentes à Praxiología Motriz enquanto Ciência da Ação Motriz, seus alcances e suas dificuldades para consolidar-se como conhecimento científico. Parlebas desenvolve uma ampla discussão com diversos autores e fundamentos teóricos que foram a base de suas investigações e publicações. Também lança um olhar retrospectivo a respeito das origens da Praxiología Motriz, assim como sua relação com a Educação Física e suas perspectivas futuras. Palavras chave: Educação Física. Conhecimento científico.Entrevista. Pesquisa cientifica

Motor Praxiology: past, present and future. Interview with Pierre Parlebas

Abstract: An interview with Pierre Parlebas is presented. Parlebas is a Ph.D. "Es lettres et sciences humaines" from Université Paris V and the Ecole Pratique des Hautes Études. He is also Emeritus Professor of Sociology and Social Sciences at Sorbonne-Paris V and Doctor Honoris Causa from the University of Lleida, Spain. In this interview, which is conducted by Jorge Ricardo Saraví, Parlebas discusses some issues related to Motor Praxiology as Science of Motor Action, its scopes and its difficulties for consolidating as scientific knowledge. Parlebas also considers the extensive work of other authors and the theoretical foundations that paved the way for its own research work and scientific publications. Finally, the origins of the Motor Praxiology, its relationship to Physical Education and its future prospects are revised.

Keywords: Physical Education. -Scientific knowledge. Scientific research. Interview

Recebido em: 09.04.2012

Aprovado em: 26.04.2012

Lovimento, Porto Alegre, v. 18, n. 01, p. 11-35, jan/mar de 2012. 
